\title{
System Analysis and Design of the Geostationary Earth Orbit All-Electric Communication Satellites
}

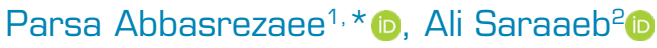

1.Sapienza University of Rome - Aerospace Engineering School - Rome - Italy. 2.Khaje Nasir Toosi University of Technology Aerospace department - Tehran - Iran.

*Corresponding author: parsa.abbasrezaee@gmail.com

\begin{abstract}
With the help of gathered data and formulas extracted from a previous conference paper, the all-electric geostationary Earth orbit (GEO) communication satellite statistical design was conducted and further studied with analytic hierarchy process (AHP) and technique for order of preference by similarity to ideal solution (TOPSIS) methods. Moreover, with the help of previously determined system parameters, the orbital ascension, orbital maintenance and deorbiting specifications, calculations and simulations were persuaded. Furthermore, a parametric subsystem design was conducted to test the methods reliability and prove the feasibility of such approach. The parametric subsystem design was used for electrical power subsystem (EPS), attitude determination and control system (ADCS), electric propulsion, telemetry, tracking and control (TT\&C) in conceptual subsystem design level, which highly relies on the satellite type and other specifications, were concluded in this paper; other subsystem designs were not of a significant difference to hybrid and chemical satellites. Eventually, the verification of the mentioned subsystems has been evaluated by contrasting the results with the Space mission engineering: the new SMAD, and subsystem design book reference.
\end{abstract}

Keywords: All-electric; GEO; AHP and TOPSIS Method; Maintenance; Deorbiting; Parametric.

\section{INTRODUCTION}

From the previous conference paper, the contrast between all-electric geostationary Earth orbit (GEO) communication and other hybrid and chemical satellite design has shown that using all-electric satellite design has many advantages. Generally, allelectric satellite designs have a 50\% total mass reduction associated with an explicit decrease of satellite fuel mass from $45 \%$ or $50 \%$ to $15 \%$ of the satellites total mass, more than $50 \%$ reduction in launcher cost and a total life span increase up to 20 years (Abbasrezaee et al. 2019). However, all-electric satellite designs have its drawbacks in their orbital ascension that can take from a minimum of 3 months up to 6 months to reach GEO depending on the satellite mass and its propulsive thrust, which is very high in comparison to few weeks of orbit ascension for chemical and hybrid satellites. Therefore, causing a long-time exposure to radiation, forcing the use of thicker shielding for sensitive electronic equipment and solar cells during all-electric satellite

Received: Jul. 06, 2020 | Accepted: Dec. 10, 2020

Peer Review History: Double Blind Peer Review.

Section Editor: T John Tharakan 
orbit ascension. The system analysis and design conducted in this paper consisted of statistical system design, orbit transfer, orbit maintenance, deorbiting specifications and parametric subsystem design. For a better understanding of the statistical design approach of the GEO all-electric satellite, AHP (analytic hierarchy process) and TOPSIS (technique for order of preference by similarity to ideal solution) methods persuaded to evaluate. Also, in this paper, orbit ascension, orbit maintenance, deorbiting [end of life (EOL)] simulation and calculation and the parametric subsystem design for electrical power subsystem (EPS), attitude determination and control subsystem (ADCS), telemetry, tracking and control subsystem (TT\&C), electric propulsion have been calculated for the GEO all-electric satellites since these subsystems are different with the hybrid and chemical ones (Wertz et al. 2011; Brow 2002).

\section{STATISTICAL OVERVIEW ON GEO ALL-ELECTRIC SATELLITE}

Statistical design and development of other methods than this paper for GEO satellites could be found in literature references (Agrawal 1986; Chetty 1991; Davidoff 1990; Griffin 1991; Martin 1996). All mentioned methods references are based on multistage algorithms and complicated parametric analysis. Besides that, at the first steps of satellite design most of the required inputs are unknown or known with uncertainty. The proposed statistical design approach below helps designers to do their jobs quickly and with the least number of requirements.

Geostationary Earth orbit communication satellites have been investigating the space since 1964. Initially used for the summer Olympics, now more than 2,000 communication satellites have communicated information to various places globally, most of which are located in GEO orbit. However, the technological developments for more than five decades from the first communication satellites until now have led to GEO all-electric communication satellites, which utilize electric propulsion for orbit transfer and their orbit maintenance during the time of mission operations (Abbasrezaee et al. 2019).

The first all-electric satellites launched into Geostationary Transfer Orbit (GTO) on September 6, 1999, was the Russian Yamal-100 satellite, which failed to reach the GEO. However, two successful all-electric satellites were launched by the SpaceX Falcon 9 v1.1, on March 2, 2015, one of which was the ABS-3A (1954 kg), and the other one was the Eutelsat 115 West B (2205 kg) (Abbasrezaee et al. 2019). It is worth to mention that for this research all the statistical data had gathered from 2015 up until March 2018 as mentioned completely in the first conference paper (Abbasrezaee et al. 2019). Most of the all-electric satellites, according to the statistical data gathered, has a range of mass between 1500-3000 kg and they all consume Xenon based fuel type with a total propellant mass in the range of 200-400 kg (Abbasrezaee et al. 2019; AST and COMSTAC 2015; FAA 2018). All-electric satellites use less fuel in their orbital ascension and orbital maintenance, which gives the all-electric satellite an advantage in an extended mission operational period that may last from 15 to 20 years. Besides, this affects the overall design reducing its bus volume at an average of $40 \%$ (Abbasrezaee et al. 2019).

\section{FORMULA AND TEST CASE}

In the conceptual system and subsystem satellites design level, critical specifications like the number of transponders for satellites, payload mass, power consumption and electrical propulsion subsystem selection should be considered. From the previous conference paper, the formulas used in the statistical system design extracted to calculate the main conceptual design parameters of a GEO telecommunication all-electric satellite with the single input of transponder number; the formulas are as seen in the linear and exponential form (Abbasrezaee et al. 2019). After putting, the first input (X) of the number of transponders in the first formula, the payload mass (Y1) will generate and, by then, all the parameters will develop by the output of the predecessor formula or related predecessor formula. Generally, all the procedures have more than 0.8 accuracy, which indicates the compatibility of this statistical data for the conceptual design level (Table 1) (Abbasrezaee et al. 2019). The Y1-Y7 in Table 1 outputs are the main conceptual system design parameters for a GEO all-electric telecommunication satellite. 
Table 1. All-electric satellite formula for calculating the conceptual level design parameters.

\begin{tabular}{|c|c|c|}
\hline Formula & $\begin{array}{l}\text { Formula } \\
\text { accuracy }\end{array}$ & Input and output \\
\hline$Y 1=65.651 \times e^{0.0409 x}$ & 0.9325 & $\begin{array}{l}\text { Input }(X) \text { : number of transponders } \\
\text { Output }(Y 1) \text { : payload mass }(\mathrm{kg})\end{array}$ \\
\hline$Y 2=1411 \times e^{0.0008 Y 1}$ & 0.9806 & $\begin{array}{c}\text { Input (Y1): payload mass }(\mathrm{kg}) \\
\text { Output (Y2): satellite total mass }(\mathrm{kg})\end{array}$ \\
\hline$Y 3=3.6147 \times e^{0.0007 Y 1}$ & 0.927 & $\begin{array}{c}\text { Input ( } \mathrm{Y} 1) \text { : payload mass }(\mathrm{kg}) \\
\text { Output (Y3): electrical power consumption of payload (kw) }\end{array}$ \\
\hline Y4 = 0.0034 Y2 + 0.9759 & 0.9887 & $\begin{array}{l}\text { Input (Y2): satellite total mass }(\mathrm{kg}) \\
\text { Output }(\mathrm{Y} 4) \text { : electrical power consumption of satellite }(\mathrm{kw})\end{array}$ \\
\hline$Y 5=5.069 e^{0.0006}$ Y2 & 0.7466 & $\begin{array}{l}\text { Input (Y2): satellite total mass }(\mathrm{kg}) \\
\text { Output (Y5): satellite volume }\left(\mathrm{m}^{3}\right)\end{array}$ \\
\hline$Y 6=0.012 Y 2+56.833$ & 0.9882 & $\begin{array}{l}\text { Input (Y2): satellite total mass }(\mathrm{kg}) \\
\text { Output (Y6): satellite cost (M\$) }\end{array}$ \\
\hline$Y 7=11.921 e^{0.0005 Y 2}$ & 0.9371 & $\begin{array}{l}\text { Input (Y2): satellite total mass }(\mathrm{kg}) \\
\text { Output (Y7): launcher cost (M\$) }\end{array}$ \\
\hline
\end{tabular}

Source: Abbasrezaee et al. (2019).

Consequently, for testing this statistical approach, a test case was conducted (Table 2) (Abbasrezaee et al. 2019). Generally, this method is divided into two parts, a part that has relied solely on formulas generated for interpolating system parameters, while the other part used data gathered to assign system parameters (Abbasrezaee et al. 2019).

Table 2. Results of formula calculation and assumption for GEO all-electric satellite test case.

\begin{tabular}{|c|c|c|}
\hline Calculations & Statistical information & Explanation \\
\hline Payload mass = 337.09 kg & $\begin{array}{l}40 \text { transponders for } 1500-2000 \mathrm{~kg} \\
\text { all electric satellites }\end{array}$ & Calculated from formula extraction \\
\hline Satellite total mass $=1847.75 \mathrm{~kg}$ & - & Calculated from formula extraction \\
\hline Payload electrical power $=4.6 \mathrm{kw}$ & 4.5 kw payload power & - \\
\hline Satellite electrical power $=7.26 \mathrm{kw}$ & 8 kw satellite power & - \\
\hline Satellite total volume $=15.36 \mathrm{~m}^{3}$ & $12-18 \mathrm{~m}^{3}$ & $3.8 \times 2 \times 2 \mathrm{~m}$ \\
\hline Satellite total cost $=$ US\$ $79 \mathrm{mi}$ & US\$ 70-90 mi & - \\
\hline Launchers cost = US\$ $30.029 \mathrm{mi}$ & $\begin{array}{l}\text { US\$ 30-35 mi half volume of } \\
\text { Falcon } 9 \text { launcher }\end{array}$ & $\begin{array}{l}\text { US\$ } 61.2 \mathrm{mi} \text { for } 8000 \mathrm{~kg} \text { payload } \\
\text { of Falcon } 9 \text { launcher to GTO }\end{array}$ \\
\hline $0.165 \mathrm{~m} \mathrm{~N}$ thrust and $300 \mathrm{~kg}$ fuel & XIPS-25 propulsion & - \\
\hline $\begin{array}{c}300 \mathrm{~kg} \text { fuel }+337 \mathrm{~kg} \text { payload mass } \\
+1250 \mathrm{~kg} \text { bus mass }=1887 \mathrm{~kg}\end{array}$ & BSS-702 SP bus & $\begin{array}{l}950-1250 \mathrm{~kg} \text { bus mass of } \\
\text { BSS-702 SP }\end{array}$ \\
\hline
\end{tabular}

Source: Abbasrezaee et al. (2019).

\section{ANALYTIC HIERARCHY PROCESS TOPSIS TEST CASE EVALUATION}

Rather than prescribing a "correct" decision, the AHP helps decision makers find one that best suits their goal and understand the problem. It provides a comprehensive and rational framework for structuring a decision problem, representing and quantifying its elements, relating those elements to overall goals and evaluating alternative solutions. Users of the AHP first decompose their decision problem into a hierarchy of more easily comprehended sub-problems, each of which can be analyzed independently. The hierarchy element can relate to any aspect of the decision problem tangible or intangible, carefully 
measured, or roughly estimated, well or poorly understood anything that applies to the decision at hand. Once the hierarchy is built, the decision-makers systematically evaluate its various elements by comparing them to each other two at a time, to impact an element above them. In making the comparisons, the decision-makers can use concrete data about the elements, but they typically use their judgement about the elements relative meaning and importance. It is the essence of the AHP that human judgments, and not just the underlying information, can be used in performing the evaluations. The AHP converts these evaluations to numerical values that can be processed and compared over the entire problem range. A numerical weight or priority is derived for each element of the hierarchy, allowing diverse and often incommensurable elements to be compared to one another rationally and consistently. This capability distinguishes AHP from other decision-making techniques. In the final step of the process, numerical priorities are calculated for each of the decision alternatives. These numbers represent the alternatives relative ability to achieve the decision goal, so they allow a straightforward consideration of the various action courses (Wikipedia 2020).

Test case evaluation conducted using AHP and TOPSIS methods (Barichard et al. 2009; Goepel 2019). Analytic hierarchy process method was conducted to generate a suitable statistical weight based on priorities given. Besides, the TOPSIS method is applied to categorize data based on their similarity to the ideal solution (Barichard et al. 2009; Goepel 2019). Analytic hierarchy process hierarchy is used since the system parameters dictate the decision-making process that will affect the function of subsystem design (Fig. 1). Analytic hierarchy process decision matrix for all-electric satellite is shown in Table 3.

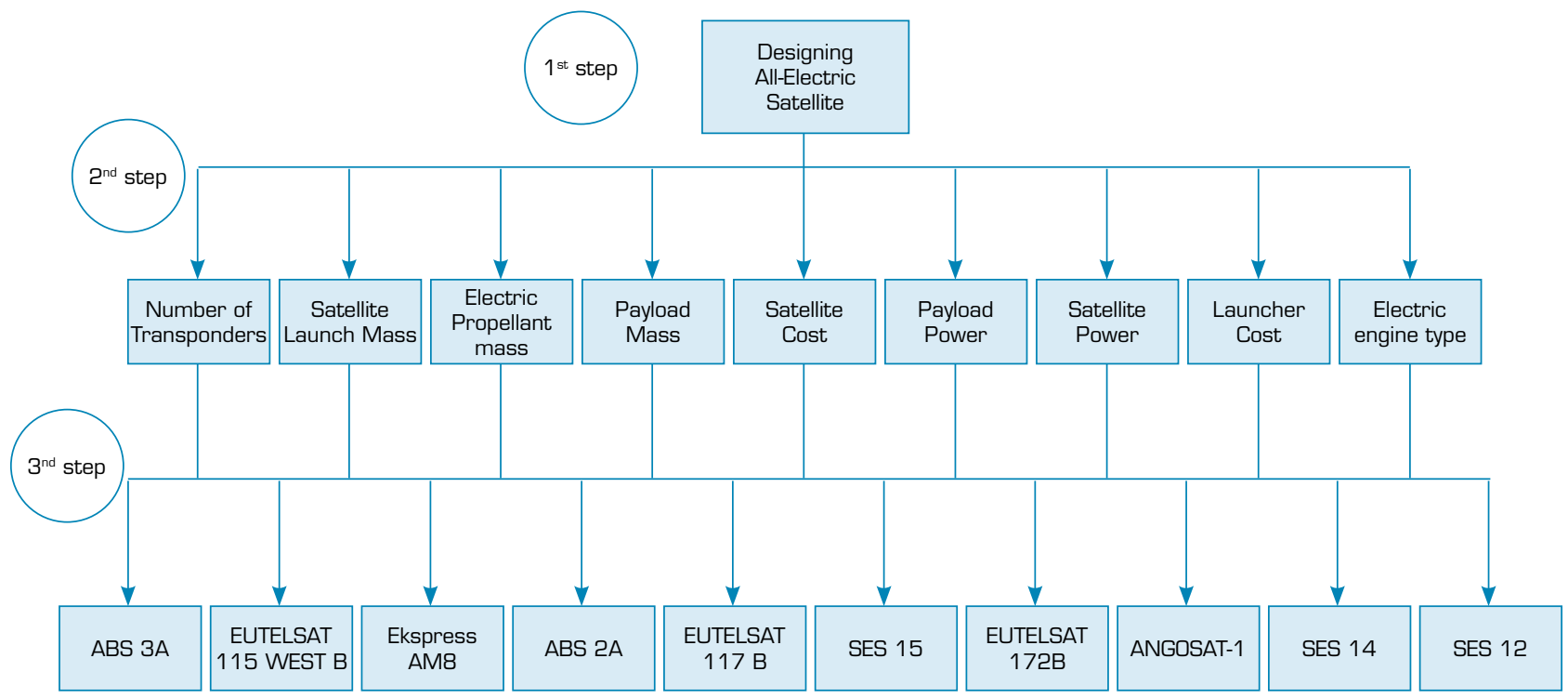

Figure 1. Analytic hierarchy process method hierarchy structure for all-electric satellite.

By utilizing an online AHP priority calculator on the website, the nine parameters of all-electric satellites have been prioritized in that calculator. Eventually, the numbers illustrate the critical factor of the number of transponders to payload mass, which means the number of transponders is five times more important to payload mass in systematic view or six times more than satellites mass, seven times more than electrical fuel mass, six times more than satellite cost, seven times more than payload power, seven times more than satellite power, five times more than launcher cost and eight times more than engine type (Goepel 2019) (Table 3).

All parameters have their factor number against the other parameters, which gave by human judgment. Therefore, the number of transponders have the most important rank and engine type with the list of important factors to the number of transponders. In Table 3, the number of the transponder to payload mass is 5, and payload mass to the number of transponders is 0.2 . Moreover, the AHP priority calculator gives a consistency ratio (CR) number that shows all the relations factors between parameters are correct if they would be under 10 (Table 4). 
Table 3. Analytic hierarchy process decision matrix table showing importance factor between all-electric satellite parameters.

\begin{tabular}{|c|c|c|c|c|c|c|c|c|c|c|}
\hline & $\begin{array}{l}\text { Decision } \\
\text { Matrix }\end{array}$ & $\begin{array}{c}1 \\
\text { Number of } \\
\text { transponders }\end{array}$ & $\begin{array}{c}2 \\
\text { Payload } \\
\text { mass }\end{array}$ & $\begin{array}{c}3 \\
\text { Satellite } \\
\text { mass }\end{array}$ & $\begin{array}{c}4 \\
\text { Electric } \\
\text { fuel mass }\end{array}$ & $\begin{array}{c}5 \\
\text { Satellite } \\
\text { cost }\end{array}$ & $\begin{array}{c}6 \\
\text { Payload } \\
\text { power }\end{array}$ & $\begin{array}{c}7 \\
\text { Satellite } \\
\text { power }\end{array}$ & $\begin{array}{c}8 \\
\text { Launcher } \\
\text { cost }\end{array}$ & $\begin{array}{c}9 \\
\text { Engine } \\
\text { type }\end{array}$ \\
\hline 1 & $\begin{array}{c}\text { Number of } \\
\text { transponders }\end{array}$ & & 5 & 6 & 7 & 6 & 7 & 7 & 5 & 8 \\
\hline 2 & Payload mass & $0 / 2$ & & 3 & 5 & 5 & 7 & 7 & 5 & 8 \\
\hline 3 & Satellite mass & $0 / 17$ & $0 / 33$ & & 5 & 4 & 7 & 7 & 4 & 8 \\
\hline 4 & $\begin{array}{l}\text { Electric fuel } \\
\text { mass }\end{array}$ & $0 / 14$ & $0 / 2$ & $0 / 2$ & & 1 & 2 & 2 & 1 & 3 \\
\hline 5 & Satellite cost & $0 / 17$ & $0 / 2$ & $0 / 25$ & 1 & & 1 & 1 & 2 & 3 \\
\hline 6 & Payload power & $0 / 14$ & $0 / 14$ & $0 / 14$ & $0 / 5$ & 1 & & 1 & 1 & 2 \\
\hline 7 & Satellite power & $0 / 14$ & $0 / 14$ & $0 / 14$ & $0 / 5$ & 1 & 1 & & 1 & 2 \\
\hline 8 & Launcher cost & $0 / 2$ & $0 / 2$ & $0 / 25$ & 1 & $0 / 5$ & 1 & 1 & & 3 \\
\hline 9 & Engine type & $0 / 12$ & $0 / 12$ & $0 / 12$ & $0 / 33$ & $0 / 33$ & $0 / 5$ & $0 / 5$ & $0 / 33$ & \\
\hline
\end{tabular}

The decision matrix value is assigned based on a simple approach, which gives the highest priority to the number of transponders. Therefore, the higher number of transponders that a satellite has, the more services it can provide. Then, criteria related to the mass of the satellite are given a second priority to the number of transponders, since mass is a critical factor affecting all designing parameters. In conclusion, the decision matrix was a balance between the satellite mass and its services. Then, the AHP pairwise comparison applied to the decision matrix to deduce every criterion (Table 4).

Table 4. Analytic hierarchy process comparison priority percentages and ranks results for decision matrix parameters.

\begin{tabular}{cccc}
\hline & Category & Priority & Rank \\
\hline 1 & Number of transponders & $40.1 \%$ & 1 \\
\hline 2 & Payload mass & $21.6 \%$ & 2 \\
\hline 3 & Satellite mass & $15.8 \%$ & 3 \\
\hline 4 & Electric fuel mass & $4.8 \%$ & 4 \\
\hline 5 & Satellite cost & $4.7 \%$ & 5 \\
\hline 6 & Payload power & $3.4 \%$ & 7 \\
\hline 8 & Satellite power & $3.4 \%$ & 7 \\
\hline 9 & Launcher cost & $4.2 \%$ & 6 \\
\hline CR\% & Engine type & $2.0 \%$ & 9 \\
\hline & & & \\
\hline
\end{tabular}

These results show that transponder and mass properties had $82.3 \%$ of the total statistical significance. Consistency ratio was equal to $6.2 \%$, which is generally an acceptable value for statistical weight. The consequences resulted from the AHP pairwise comparison are essential to apply the TOPSIS method and for the ideal solution the assumptions below were presumed, noting that engine type has been converted to quantitative value from one to four from best to worst case, respectively, which is based on the previous statistical analysis of engine performance (Table 5) (Abbasrezaee et al. 2019). 
Table 5. Ideal best/worst value assumptions for decision matrix parameters.

\begin{tabular}{ccccccccccc}
\hline & $\begin{array}{c}\text { Number of } \\
\text { transponders }\end{array}$ & $\begin{array}{c}\text { Payload Satellite } \\
\text { mass }\end{array}$ & $\begin{array}{c}\text { Electric } \\
\text { mass }\end{array}$ & $\begin{array}{c}\text { Satellite } \\
\text { fuel mass }\end{array}$ & $\begin{array}{c}\text { Payload } \\
\text { cost }\end{array}$ & power & $\begin{array}{c}\text { Satellite } \\
\text { power }\end{array}$ & $\begin{array}{c}\text { Launcher } \\
\text { cost }\end{array}$ & $\begin{array}{c}\text { Engine } \\
\text { type }\end{array}$ \\
\hline V+ (ideal best value) & $\operatorname{Max}$ & Min & Min & Min & Min & Min & Min & Min & Min \\
\hline V- (ideal worst value) & $\operatorname{Min}$ & $\operatorname{Max}$ & $\operatorname{Max}$ & $\operatorname{Max}$ & $\operatorname{Max}$ & $\operatorname{Max}$ & $\operatorname{Max}$ & $\operatorname{Max}$ & $\operatorname{Max}$ \\
\hline
\end{tabular}

The TOPSIS was conducted only for all-electric satellite data gathered from the previous paper, in which statistical performance was calculated and, based on it, every satellite ranked including the test case (Table 6). Satellites rank differ because of all priorities and satellites, which have low total mass, a high number of transponders and low payload mass. Most of the satellite data are in the conference paper, such as satellite total mass, number of transponders, launcher types, etc. Table 6, the ANGOSAT-1, test case satellite and EUTELSAT $117 \mathrm{~B}$ are the best in rank with AHP and TOPSIS evaluation, since these satellites have 40-60 number of transponders, which is the highest factor to choose. Besides, the payload mass and satellite total mass is low for these satellites, which has the second and third factor in evaluations. The test case satellite has 40 transponders and $1887 \mathrm{~kg}$ satellite total mass, $337 \mathrm{~kg}$ payload mass, lower than the average $2000 \mathrm{~kg}$ satellite total mass and below $400 \mathrm{~kg}$ of average payload mass. ANGOSAT-1 has $1647 \mathrm{~kg}$ total mass with near 30 transponders; however, the EUTELSAT $172 \mathrm{~B}$ has $3350 \mathrm{~kg}$ total mass with 45 transponders, which the total mass factor leads this option to be in 10 ranks.

Table 6. The TOPSIS method performance and rank results for selected all-electric satellite.

\begin{tabular}{ccc}
\hline Name of satellite & Performance [\%] & Rank \\
\hline ABS 3A & 91.64183676 & 5 \\
\hline EUTELSAT 115 WEST B & 88.50431894 & 8 \\
\hline Ekspress AM8 & 89.01029446 & 7 \\
\hline ABS 2A & 90.9337616 & 6 \\
\hline EUTELSAT 117 B & 91.74572388 & 4 \\
\hline SES 15 & 83.84680972 & 9 \\
\hline EUTELSAT 172B & 54.32213346 & 10 \\
\hline ANGOSAT-1 & 93.60404619 & 11 \\
\hline SES 14 & 23.85183676 & 12 \\
\hline SES 12 & 9.898662583 & 3 \\
\hline Test case & 93.47590506 & 1 \\
\hline V+ (ideal best value) & 99.99999949 & 13 \\
\hline V- (ideal worst value) & $5.4293 E-07$ & \\
\hline
\end{tabular}

From the results shown in the table, it is possible to conclude, based on statistical performance values, that the test case parameters chosen satisfy the criteria given enough and have an excellent performance of $93.47590506 \%$. However, the test case did rank directly the best to ideal ANGOSAT-1 was better and ranked the second to the excellent best value with a small difference in performance that can be ignored. The method conducted is realistic and accurately balanced and tuned towards the goal intended, which is having the best balance between the satellite mass and services.

\section{ORBIT TRANSFER, ORBIT MAINTENANCE AND DEORBITING}

In the simulation, all-electric satellite total mass in statistical data offers a clear suggestion to divide all-electric satellites into four satellite mass categories 1500, 2000, 2500 and $3000 \mathrm{~kg}$. This division eased comparison between these new sub mass categories, which simplified the calculation of main satellite characteristics, such as orbit transfer, orbital maintenance, deorbiting fuel mass consumption, orbit transfer time and thrust needed with different launchers and different electric propulsion subsystem 
characteristics (Abbasrezaee et al. 2019). Geostationary Earth orbit characteristics were considered in the simulations, such as orbit inclination (i) $0^{\circ}$ (with 0.01 accuracy), deorbiting (e) $0^{\circ}$ (with 0.001 accuracy), and semi-major axis (a) $42160 \mathrm{~km}$ (with 0.01 accuracy). Four launchers were chosen from data sampled based on their high percentage of launcher use in statistic paper (Abbasrezaee et al. 2019). Normally, the electric propulsions subsystem consists of two pair of thrusters mounted on an adjustable 3-axis arm (Luebberstedt et al. 2018). The 3-axis arm is advantageous since it provides better thermal control, less electromagnetic interference (EMI) and better compatibility with assembly integration and test (AIT) for propulsion wiring and propulsion fuel pumping (Luebberstedt et al. 2018; Naclerio et al. 2012; Senbely et al. 2017). Earth to GTO and GEO, illustrated in Fig. 2, shows launchers mission from Earth to the beginning of the GTO (Proton-M-Brize-M launcher) and satellites, which start from the GTO to GEO (Fig. 2 and Table 7) (Zak 2021).

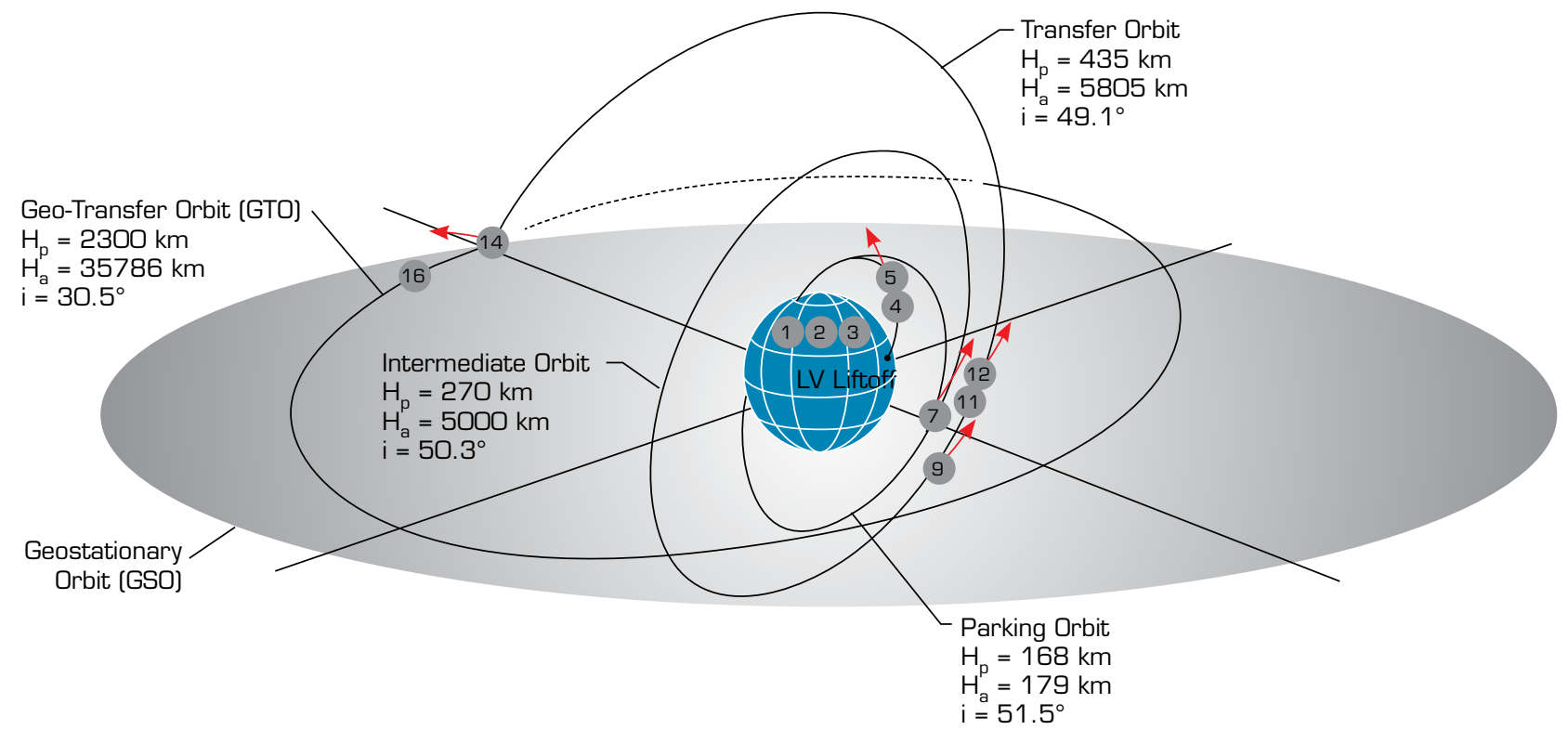

Figure 2. Proton-M-Brize-M launcher GTO to GEO mission. Source: Zak (2021).

Table 7. Sampled GTO launcher specifications from references for simulations.

\begin{tabular}{ccccc}
\hline Specification & Soyuz-fregat & Proton-M-Brize-M & Falcon 9 v, 11 & Ariane 5 ECA \\
\hline Inclination (i) & 6 & 30.5 & 28.5 & 6 \\
\hline Altitude of perigee (ap) & 250 & 2300 & 185 & 250 \\
\hline Altitude of apogee (aa) & 35950 & 35786 & 35786 & 35943 \\
\hline
\end{tabular}

Source: AST and COMSTAC (2015) and FAA (2018).

For GTO simulation, the Soyuz-Fregat launcher was chosen, since it has a low GTO inclination release and proper orbit specification. This issue will decrease fuel mass consumption for orbit ascension of the satellite (Tables 8-12) (FAA 2018; Lugtu 1990).

The System Tool Kit (STK) software is used to calculate the fuel mass consumption and time for three main modes of orbit ascension (GTO), orbit maintenance (GEO) and deorbiting. One pair arm thruster force vector is towards the direction the satellite should go in orbit ascension and deorbiting mode. Still, this vector will be towards the satellite center of mass during the orbit maintenance mode in GEO orbit (Luebberstedt et al. 2018; Naclerio et al. 2012). For comparison between different propulsion subsystem performances of different satellite mass categories, Soyuz specification presumed as launcher specification with four different satellite propulsion subsystem specifications (Table 8). This use of different propulsions showed different variations in fuel mass consumption of orbit ascension and time (per days, months) mentioned in Table 8; these results were simulated for all the assumed mass categories (1500 to $3000 \mathrm{~kg}$ ). 
Table 8. Sampled electric propulsion specification for simulations.

\begin{tabular}{ccccccc}
\hline Propulsion Specification & $\begin{array}{c}\text { Thrust } \\
\text { (N) }\end{array}$ & $\begin{array}{c}\text { ISP } \\
\text { [s] }\end{array}$ & $\begin{array}{c}\text { Efficiency } \\
\text { (\%) }\end{array}$ & $\begin{array}{c}\text { Type of } \\
\text { thruster }\end{array}$ & Name of company & Country \\
\hline XIPS-25 (Goebel et al. 2009) & 0.165 & 3550 & 71 & ION & L-3 Communication & USA \\
\hline SPT-140D (Kim 2012) & 0.29 & 1770 & 68 & Hall-effect & OKB Fakel & Russia \\
\hline PPS 1350 (Safran 2021) & 0.089 & 1700 & 50 & Hall-effect & $\begin{array}{c}\text { Snecma (Safran } \\
\text { Aircraft Engine) }\end{array}$ & French \\
\hline BHT2OK (Leporini et al. 2016) & 1.08 & 2750 & 72 & Hall-effect & Busek & USA \\
\hline
\end{tabular}

Source: Goebel et al. (2009), Kim (2012), Safran (2021) and Leporini et al. (2016).

Table 9. Orbit transfer GTO to GEO results of SPT-140D propulsion calculated with STK.

\begin{tabular}{cccc}
\hline $\begin{array}{c}\text { Weight of all electric } \\
\text { satellites }(\mathrm{kg})\end{array}$ & Total xenon fuel $\mathbf{k g})$ & $\begin{array}{c}\text { Fuel consumption for orbit } \\
\text { transfer }(\mathrm{kg})\end{array}$ & Time (day-month) \\
\hline 1500 & 250 & 143.98 & $99.74-3.32$ \\
\hline 2000 & 300 & 189.105 & $131-4.366$ \\
\hline 2500 & 350 & 234.36 & $162.36-5.41$ \\
\hline 3000 & 400 & 279.59 & $193.69-6.456$ \\
\hline
\end{tabular}

Table 10. Orbit transfer GTO to GEO results of XIPS-25 propulsion calculated with STK.

\begin{tabular}{cccc}
\hline $\begin{array}{c}\text { Weight of all electric } \\
\text { satellites }(\mathrm{kg})\end{array}$ & Total xenon fuel $\mathbf{k g})$ & $\begin{array}{c}\text { Fuel consumption for orbit } \\
\text { transfer }(\mathrm{kg})\end{array}$ & Time (day-month) \\
\hline 1500 & 200 & 71.238 & $173.96-5.8$ \\
\hline 2000 & 250 & 71.238 & $232.67-7.75$ \\
\hline 2500 & 300 & 108.41 & $283.25-9.44$ \\
\hline 3000 & 300 & 129.72 & $338.88-11.28$ \\
\hline
\end{tabular}

Table 11. Orbit transfer GTO to GEO results PPS 1350 propulsion calculated with STK.

\begin{tabular}{cccc}
$\begin{array}{c}\text { Weight of all electric } \\
\text { satellites }(\mathrm{kg})\end{array}$ & Total xenon fuel $\mathbf{( k g )}$ & $\begin{array}{c}\text { Fuel consumption for orbit } \\
\text { transfer }(\mathbf{k g})\end{array}$ & Time (day-month) \\
\hline 1500 & 250 & 149.67 & $324.49-10.82$ \\
\hline 2000 & 300 & 196.706 & $426.46-14.21$ \\
\hline 2500 & 350 & 243.72 & $528.37-17.61$ \\
\hline 3000 & 400 & 290 & $630.42-21$ \\
\hline
\end{tabular}

Table 12. Orbit transfer GTO to GEO results BHT20K propulsion Calculated with STK.

\begin{tabular}{cccc}
\hline $\begin{array}{c}\text { Weight of all electric } \\
\text { satellites }(\mathrm{kg})\end{array}$ & Total xenon fuel $\mathbf{k g})$ & $\begin{array}{c}\text { Fuel consumption for orbit } \\
\text { transfer }(\mathbf{k g})\end{array}$ & Time (day-month) \\
\hline 1500 & 200 & 91.41 & $28.53-0.95$ \\
\hline 2000 & 250 & 1120 & $37.76-1.2$ \\
\hline 2500 & 300 & 150.56 & $46.99-1.56$ \\
\hline 3000 & 350 & 180 & $56.21-1.87$ \\
\hline
\end{tabular}


Trajectory optimization was not utilized and the trajectory chosen was by default; therefore, by intuition, the amount of fuel consumption and the time to reach GEO can be reduced. The BHT20K propulsion based on the simulated results is the best time from GTO to GEO and in fuel amount consumption. However, the electric power consumption of BHT20K propulsion contradicts since, based on the hypothesis of design of this study, a satellite cannot merely provide this amount of electric power or in best case scenario dedicating such a considerable amount of electrical power for this purpose will decrease the margin of other functionalities. Consequently, the BHT20K propulsion filtered out. As a result, XIPS-25 was the best in all regards and it was selected based on the simulated results among other propulsion subsystems for all-electric satellite design.

Orbit maintenance is essential for all space satellites, especially for GEO communication satellites, because of space satellite environment disturbances, such as solar radiation pressure, third body gravity effect (Sun and Moon gravity) and Earth gravity harmonies. Furthermore, GEO satellites need very high nadir pointing accuracy for their telecommunication antenna reflectors to function appropriately. Geostationary Earth orbit satellites have North/South orbit correction and East/West orbit corrections. North/South orbit correction is utilized for inclination (i) disturbances and East/West orbit corrections are used for eccentricity (e) and longitudinal disturbances corrections. Orbital maintenance was not subjected to any simulation, it was directly calculated based on the formula provided by Nasa Handbook in reference for 20 years of commission for 2000 and $3000 \mathrm{~kg}$ all-electric satellite (Lovell and O’Maley 1970; Lugtu 1990). Besides, orbital maintenance was not calculated for all the sub mass categories since relatively the contrasted fuel mass consumption between mass categories is small in amount (1500-2000 and 2500-3000 kg). The results for North/South and East/West orbit corrections have been calculated from reference formula for two all-electric satellite mass categories and the result in Tables 13-15 show that more than $95 \%$ of the fuel consumed in orbital maintenance will be consumed in North/South corrections (Lovell and O’Maley 1970; Lugtu 1990).

Table 13. Twenty years North/South orbit correction for all-electric satellites calculated results.

\begin{tabular}{cccc}
\hline Parameters & 2000 kg satellite & 3000 kg satellite \\
\hline Days between each maneuver & 4.32 \\
\hline Total number of maneuvers in 20 years & \multicolumn{3}{c}{1691} \\
\hline Total $\Delta$ v in 20 years $(\mathrm{m} / \mathrm{s})$ & \multicolumn{3}{c}{907.245} \\
\hline Total fuel consumption in 20 years $(\mathrm{kg})$ & 71 & & 105.82 \\
\hline
\end{tabular}

Table 14. Twenty years East/West orbit correction for all-electric satellites calculated results.

\begin{tabular}{ccc}
\hline Parameters & 2000 kg satellite & 3000 kg satellite \\
\hline Days between each maneuver & 10 \\
\hline Total number of maneuvers in 20 years & 730 \\
\hline Total $\Delta \mathrm{v}$ in 20 years $(\mathrm{m} / \mathrm{s})$ & 33.58 & \\
\hline Total fuel consumption in 20 years $(\mathrm{kg})$ & 2.6 & \\
\hline
\end{tabular}

Table 15. Sum of 20 years orbit maintenance and correction results from Tables 13 and 14.

\begin{tabular}{ccc}
\hline Parameters & 2000 kg satellite & 3000 kg satellite \\
\hline Total $\Delta v$ in 20 years $(\mathrm{m} / \mathrm{s})$ & \multicolumn{2}{c}{940.825} \\
\hline Total fuel consumption in 20 years $(\mathrm{kg})$ & 73.6 & 109.71 \\
\hline
\end{tabular}

The deorbiting process is essential for eliminating obsolete telecommunication and weather forecasting GEO satellite, where all deorbiting satellites will settle in GEO graved orbit (500 hm above their missions' orbit) (Wikipedia 2021). Therefore, GEO deorbiting simulated in STK for different propulsion subsystem for 2000 and $3000 \mathrm{~kg}$ all-electric satellite systems (Tables 16 and 17). 
Table 16. Deorbiting $2000 \mathrm{~kg}$ GEO telecommunication all-electric satellite with different propulsions STK simulated results.

\begin{tabular}{ccccc}
\hline Parameters & XIPS-25 & SPT-140D & BHT20K & PPS1350 \\
\hline Total fuel consumption $(\mathrm{kg})$ & 3.02 & 6.47 & 4.18 & 6.76 \\
\hline Time (days) & 6.5 & 4.48 & 1.21 & 14.65 \\
\hline$\Delta \mathrm{V}(\mathrm{m} / \mathrm{s})$ & 55.68 & 55.68 & 55.84 & 55.84 \\
\hline
\end{tabular}

Table 17. Deorbiting $3000 \mathrm{~kg}$ GEO telecommunication all-electric satellite with different propulsions STK simulated results.

\begin{tabular}{ccccc}
\hline Parameters & XIPS-25 & SPT-140D & BHT20K & PPS1350 \\
\hline Total fuel consumption $(\mathrm{kg})$ & 4.84 & 9.70 & 6.25 & 10.1 \\
\hline Time (days) & 11.82 & 6.72 & 1.80 & 21.9 \\
\hline$\Delta \mathrm{V}(\mathrm{m} / \mathrm{s})$ & 55.84 & 55.84 & 55.84 & 55.84 \\
\hline
\end{tabular}

The XIPS-25 propulsion is the most efficient propulsion subsystem and consumes the least amount of Xeon fuel. Fuel consumption simulated and calculated for all the main modes associated with the satellite in orbit (orbit ascension, orbit maintenance, and deorbiting). This result for 2000 and $3000 \mathrm{~kg}$ presumed system in 277-409 kg fuel mass for PPS 1350 propulsion, 165.7-244.5 kg fuel mass for XIPS-25 propulsion, 270-400 kg fuel mass for SPT-140D propulsion, and 197.8-295.9 kg fuel mass for BHT20K propulsion. All data extracted from the simulation are accurate since the input data used from real propulsions with different specifications.

\section{Subsystem conceptual parametric design}

Subsystem parametric design consists of using different formulas for each subsystem calculation, gathering statistical information about various parts used in the same class of satellites and utilizing essential input data from datasheets to choose different subsystems information needed in formulas. All-electric satellites are unique in their electrical propulsion subsystem design, practically the 3-axis arm configuration, which necessitates an efficient enough electrical power supply providing the needed electrical power. Electric power generation and distribution (EPS), ADCS and propulsion, which are the subsystems to have differences in all-electric design with hybrid and chemical ones, were subjected to the parametric design process, which will be represented later in this section. Since this satellite is a communication one, in this case, the design of the TT\&C and payload subsystem should also be conduct with the parametric design. Not forgetting that for all-electric satellites, a thicker protective shielding is required for its long exposure to Van Allen radiation during transferring orbit from GTO to GEO to protect solar cells and electronic equipment.

\section{Telemetry and tele-command and communication payload system}

Telemetry, tracking and control subsystem transfers and receives telemetry beckons data from the ground station. For GEO telecommunication satellite, multi-communication missions could be considered for GEO telecommunication satellites, such as fix satellite services (FSS), movable satellite services (MSS), broadcast satellite services (BSS), etc. (Mirshams et al. 2015). Therefore, TT\&C parametric design starts with selecting payload communications and TT\&C related subsystem parts from data available and then it ends with calculating payload mass and electric power consumption. Telemetry, tracking and control subsystem consists of antenna, antenna reflector, traveling-wave tube amplifier (TWTA), multiplexer (input, output), LNA and transponders, where the chosen transponder dictates and puts the main terms in about other parts. Selected communication and TT\&C subsystem parts set from Thales Alenia, Tesat Spacecom, RUAG and other companies. The average number of transponders for all-electric satellites were in the range of 40 to 60 transponders, where their KU, C and KA bands were the most used types for all-electric satellite, results and calculation conducted are in Tables 18 and 19. The number of transponders is 65, five more than the average presented, to have adequate design quality for payload mass and power budget. 
Table 18. Telemetry, tracking and control mass and power calculated results.

\begin{tabular}{|c|c|c|c|c|c|c|}
\hline Parameters & Numbers & Dimension & $\begin{array}{l}\text { Power cons } \\
\text { (w) }\end{array}$ & $\begin{array}{l}\text { Mass } \\
{[\mathrm{kg}]}\end{array}$ & $\begin{array}{c}\text { Total power } \\
\text { cons }(w)\end{array}$ & $\begin{array}{c}\text { Total mass } \\
{[\mathrm{kg}]}\end{array}$ \\
\hline $\begin{array}{c}\mathrm{KU} \text { telemetry } \\
\text { (beacon) transponder }\end{array}$ & $\begin{array}{l}4 \text { (2 } \\
\text { redundant) }\end{array}$ & $\begin{array}{c}215 \times 162 \times \\
50 \mathrm{~mm}^{3}\end{array}$ & 11.5-15.3 & 1.4 & 5.6 & 30.6 \\
\hline LNA & 4 & $\begin{array}{c}41 \times 20 \times \\
9 \mathrm{~mm}^{3}\end{array}$ & 0.5 & 0.032 & 0.128 & 2 \\
\hline Input multiplexer & 1 & 50 channels & - & $\begin{array}{l}0.14 \text { per } \\
\text { channel }\end{array}$ & 7 & - \\
\hline Output multiplexer & 1 & 50 channels & - & $\begin{array}{l}0.14 \text { per } \\
\text { channel }\end{array}$ & 7 & - \\
\hline TWTA & 4 & $\begin{array}{l}282.5 \times 75 \times \\
62.5 \mathrm{~mm}^{3}\end{array}$ & 30 & $0.76-3.2$ & 12.8 & 60 \\
\hline $\mathrm{KU}$ antenna & 4 & - & - & 0.5 & 2 & - \\
\hline Antenna reflector & 1 & 222 mm & 0 & 0.5 & 0.5 & 0 \\
\hline $\begin{array}{c}\text { Total power } \\
\text { consumption (w) }\end{array}$ & \multicolumn{6}{|c|}{92.6} \\
\hline Total weight $(\mathrm{kg})$ & \multicolumn{6}{|c|}{33} \\
\hline
\end{tabular}

Table 19. Telecommunication payload mass and power budget results.

\begin{tabular}{|c|c|c|c|c|c|c|}
\hline Parameters & Numbers & Dimension & $\begin{array}{l}\text { Power cons } \\
\text { [w] }\end{array}$ & $\begin{array}{c}\text { Mass } \\
{[\mathrm{kg}]}\end{array}$ & $\begin{array}{l}\text { Total power } \\
\text { cons }(w)\end{array}$ & $\begin{array}{c}\text { Total mass } \\
\text { [kg] }\end{array}$ \\
\hline KU transponder & 40 & $\begin{array}{c}72 \times 245 \times \\
165 \mathrm{~mm}^{3}\end{array}$ & 20 & 1.5 & 800 & 60 \\
\hline KU antenna & 40 & - & - & 0.5 & - & 20 \\
\hline C transponder & 15 & $\begin{array}{c}150 \times 282 \times \\
195 \mathrm{~mm}^{3}\end{array}$ & 44 & 4 & 660 & 60 \\
\hline C antenna & 15 & - & - & 0.7 & - & 10.5 \\
\hline KA transponder & 5 & $\begin{array}{c}215 \times 140 \times \\
175 \mathrm{~mm}^{3}\end{array}$ & 40 & 3 & 200 & 15 \\
\hline KA antenna & 5 & - & - & 0.8 & - & 4 \\
\hline S transponder & 5 & $\begin{array}{c}253 \times 175 \times \\
130 \mathrm{~mm}^{3}\end{array}$ & $13-30$ & 3 & 150 & 15 \\
\hline S antenna & 5 & - & - & 0.8 & - & 4 \\
\hline LNA & 80 & $\begin{array}{c}41 \times 20 \times \\
9 \mathrm{~mm}^{3}\end{array}$ & 0.5 & 0.032 & 40 & 2.6 \\
\hline Input multiplexer & 5 & 50 channels & - & $\begin{array}{l}0.14 \text { per } \\
\text { channel }\end{array}$ & - & 35 \\
\hline Output multiplexer & 5 & 5 & - & $\begin{array}{c}0.14 \text { per } \\
\text { channel }\end{array}$ & - & 35 \\
\hline TWTA & 80 & 80 & 30 & $0.76-3.2$ & 2400 & 160 \\
\hline Antenna reflector & $3-6$ & $3-6$ & 0 & 5 & - & $15-30$ \\
\hline $\begin{array}{c}\text { Total power } \\
\text { consumption }(w)\end{array}$ & \multicolumn{6}{|c|}{4190} \\
\hline Total weight $(\mathrm{kg})$ & \multicolumn{6}{|c|}{451.1} \\
\hline
\end{tabular}




\section{Electrical power production and distribution subsystem design}

Electric power supply and distribution consist of solar cell panels, battery packs, electric power regulators, power distribution units and cables. The latest technological developments in batteries and solar cells should be considered since they significantly affect output design parameters. The scrutinizing of statistical data related to the electrical power subsystem leads the consideration of two modes for all-electric satellites such as $8 \mathrm{~kW}$ for $2000 \mathrm{~kg}$ and $12 \mathrm{~kW}$ for $3000 \mathrm{~kg}$ satellites for power production EOL. Besides, batteries and solar cells type considered from the statistical results to be Li-ion (VES 180) from the France SAFT company and 3G30C-Advanced TJ (Ga-Ar) from the AZUR SPACE company, respectively. Most of the formula have been used from the NASA handbooks (Martinez-Sanchez and Pollard 1998; Corey and Pidgeon 2009; Flood and Weinberg 1994; Rauschenbach 1976). The primary required calculations for the electric power subsystem are illustrated in Table 20.

Table 20. Primary calculated results for electric power subsystem.

\begin{tabular}{|c|c|c|}
\hline Parameters & Results for $8 \mathrm{~kW}$ EOL & Results for $12 \mathrm{~kW}$ EOL \\
\hline$P=$ orbit period $(\mathrm{min})$ & 1436 & 1436 \\
\hline $\mathrm{TE}=$ eclipse period $(\mathrm{min})$ & 72 & 72 \\
\hline Psa = power generated solar array (W) & $10,061.4376$ & $15,092.156$ \\
\hline$P C=$ power output from one cell $(\mathrm{W})$ & 0.728 & 0.728 \\
\hline $\mathrm{NC}=$ number of arrays for Psa & 13,821 & 20,731 \\
\hline AArray = solar area $\left(\mathrm{m}^{2}\right)$ & 46.35 & 69.52 \\
\hline $\begin{array}{c}\mathrm{Vmp}=\text { solar cell voltage after radiation (at EOL) at maximum } \\
\text { temperature (voltage) }\end{array}$ & 1.7852 & 1.7852 \\
\hline NS = number of solar in series & 59 & 59 \\
\hline $\begin{array}{c}\text { Imp = maximum current at } 80^{\circ} \mathrm{C} \text { temperature taking into account for } \\
\text { the maximum distance loss }(\mathrm{A})\end{array}$ & 0.484 & 0.484 \\
\hline VCell = solar cell string voltage (voltage) & 1.913 & 1.913 \\
\hline VString = voltage of string $(\mathrm{v})$ & 112.8 & 112.8 \\
\hline Pstring = power of string $(\mathrm{w})$ & 48.08 & 48.08 \\
\hline $\mathrm{NP}=$ number of cells in parallel & 228 & 342 \\
\hline ANet $=$ area of solar cells $\left(\mathrm{m}^{2}\right)$ & 40.5 & 60.89 \\
\hline Total $A=$ total area with space between cells & 45 & 67.65 \\
\hline MArray = mass of arrays $(\mathrm{kg})$ & 21 & 31.3 \\
\hline $\mathrm{CV}=$ capacity of batteries $(\mathrm{w} / \mathrm{h})$ & $13,333.34$ & 20,000 \\
\hline MBattery = mass of batteries $(\mathrm{kg})$ & 81 & 122 \\
\hline MPGS = mass of arrays, batteries, regulations and cabling $(\mathrm{kg})$ & 112 & 168 \\
\hline
\end{tabular}

For calculations of the electrical power subsystem expenses, the mass of solar cell panels should be considered. Without this consideration, the mean average mass calculated can be meager and unrealistic. However, to start the calculations, solar cell panels hinges, or any other detailed overview of the system was not considered. This resulted in 112 and $168 \mathrm{~kg}$ for 8 and $12 \mathrm{~kW}$ electric power EOL of the satellite. After that, the number of cells in series and strings have been calculated for 8 and $12 \mathrm{~kW}$ EOL satellites. By considering that solar panels consist of many sandwich panels, hinges and opening mechanism. Knowing that almost all GEO satellites solar panels consist of equally two-sided solar wings from the top and bottom of the satellite surface, this configuration is chosen during calculations. The calculation for considering solar panel size is illustrated in Table 21. 
Table 21. Calculations for considering solar panels size.

\begin{tabular}{ccc}
\hline Parameters & 8 kw EOL & 12 kw EOL \\
\hline Solar area $\left(\mathrm{m}^{2}\right)$ & 45 & 67.65 \\
\hline Number of cells in series & 59 & 59 \\
\hline Number of strings (parallel) & 228 & 342 \\
\hline Dimension of single solar cell $\left(\mathrm{mm}^{2}\right)$ & \multicolumn{2}{c}{$40 \times 80$} \\
\hline Max panel dimension $\left(\mathrm{m}^{2}\right)$ & \multicolumn{2}{c}{$2.8 \times 3.4$} \\
\hline
\end{tabular}

The total wing area, number of panels, the square panel dimensions and the panel area have been calculated and optimized for 8 and $12 \mathrm{~kW}$ EOL power of all-electric satellites (Tables 22, 23).

Table 22. Results of calculations after considering solar panels size.

\begin{tabular}{ccccccccccc}
\hline Parameters & \multicolumn{4}{c}{$\mathbf{8}$ kw EOL } & & \multicolumn{3}{c}{ 12 kw EOL } \\
\hline Wing area $\left(\mathrm{m}^{2}\right)$ & 22.5 & 22.5 & 22.5 & 22.5 & & 33.825 & 33.825 & 33.825 & 33.825 \\
\hline Number of panels & 2 & 3 & 4 & 5 & & 3 & 4 & 5 & 6 \\
\hline Panel area $\left(\mathrm{m}^{2}\right)$ & 11.25 & 7.5 & 5.62 & 4.5 & & 11.275 & 8.456 & 6.765 & 5.6 \\
\hline Dimension of square panel $\left(\mathrm{m}^{2}\right)$ & 5.625 & 3.75 & 2.81 & 2.25 & & 5.63 & 4.228 & 3.38 & 2.8 \\
\hline
\end{tabular}

Table 23. The contrast between different numbers of panels per wings.

\begin{tabular}{ccc}
\hline Parameters & $\mathbf{8}$ kw EOL & 12 kw EOL \\
\hline Number of panels per wing & 3 & 6 \\
\hline N (cells in series) & 59 & 59 \\
\hline N (cells in parallel) & 38 & 29 \\
\hline A length per wing mm & 3114 & 2376 \\
\hline B width per wing mm & 2476 & 2476 \\
\hline Panel area (m²) & 7.71 & 5.89 \\
\hline Total solar array area $\left(\mathrm{m}^{2}\right)$ & 46.26 & 70.68
\end{tabular}

The sandwich panels, adhesive and panel coverings types are considered AL5056-50-3, K13C2U and Hexply 954-6 from the statistical analysis. After making a tradeoff between the weight, the number of panels and available panel sizes, the 3-panels form for $8 \mathrm{~kW}$ and 6-panels form for $12 \mathrm{~kW}$ has been considered for each wing.

The total mass budget for 8 and $12 \mathrm{~kW}$ EOL electric power subsystem calculated 283.14 and $439.8 \mathrm{~kg}$, respectively (Table 24).

Table 24. Results of total solar arrays mass budget for two wings.

\begin{tabular}{|c|c|c|c|c|c|}
\hline Parameters & $\begin{array}{c}\text { Panels weight } \\
\text { [kg] }\end{array}$ & $\begin{array}{c}\text { Number of } \\
\text { panels per wing }\end{array}$ & $\begin{array}{l}\text { Mass of hinges } \\
{[\mathrm{kg}](2 \mathrm{pcs} / \text { panel] }}\end{array}$ & $\begin{array}{l}\text { Mass of HDRM } \\
\text { [kg] (4 pcs/panel) }\end{array}$ & $\begin{array}{c}\text { Total array mass } \\
{[\mathrm{kg}]}\end{array}$ \\
\hline 8 kw EOL & 39.39 & 3 & \multirow{2}{*}{1.5} & \multirow{2}{*}{1.2} & 283.14 \\
\hline 12 kw EOL & 28.85 & 6 & & & 439.8 \\
\hline
\end{tabular}

\section{Propulsion subsystem design}

The propulsion subsystem design should be conducted for hybrid and chemical satellites to recognize the thruster number and configuration. However, the all-electric satellite configuration is the 3 -axis arm configuration by convention and there is 
no need to consider other designing options since it is nearly optimal. As shown in the previous section, XIPS-25 propulsion was best in almost all main aspects of consideration (specific impulse [ISP], thrust, weight, electric power consumption) for an electrical propulsion subsystem. All-electric propulsion units consist of xenon tank (XST), fill and drain valve (FDV), pyro valve (PV), xenon filter (XEF), power processing unit (PPU), thruster module assembly (TMA) and Xenon Regulator and Feed System (XRFS). Power consumption varies significantly between orbit raising and orbit maintenance modes. Hence, the orbit-raising mode consumes more electric fuel mass for a longer duration to deliver the satellite. The electrical power would be twice as near as orbit maintenance mode (Table 25) (Naclerio et al. 2012; Corey and Pidgeon 2009).

Table 25. All electric satellites propulsion subsystem design parameters.

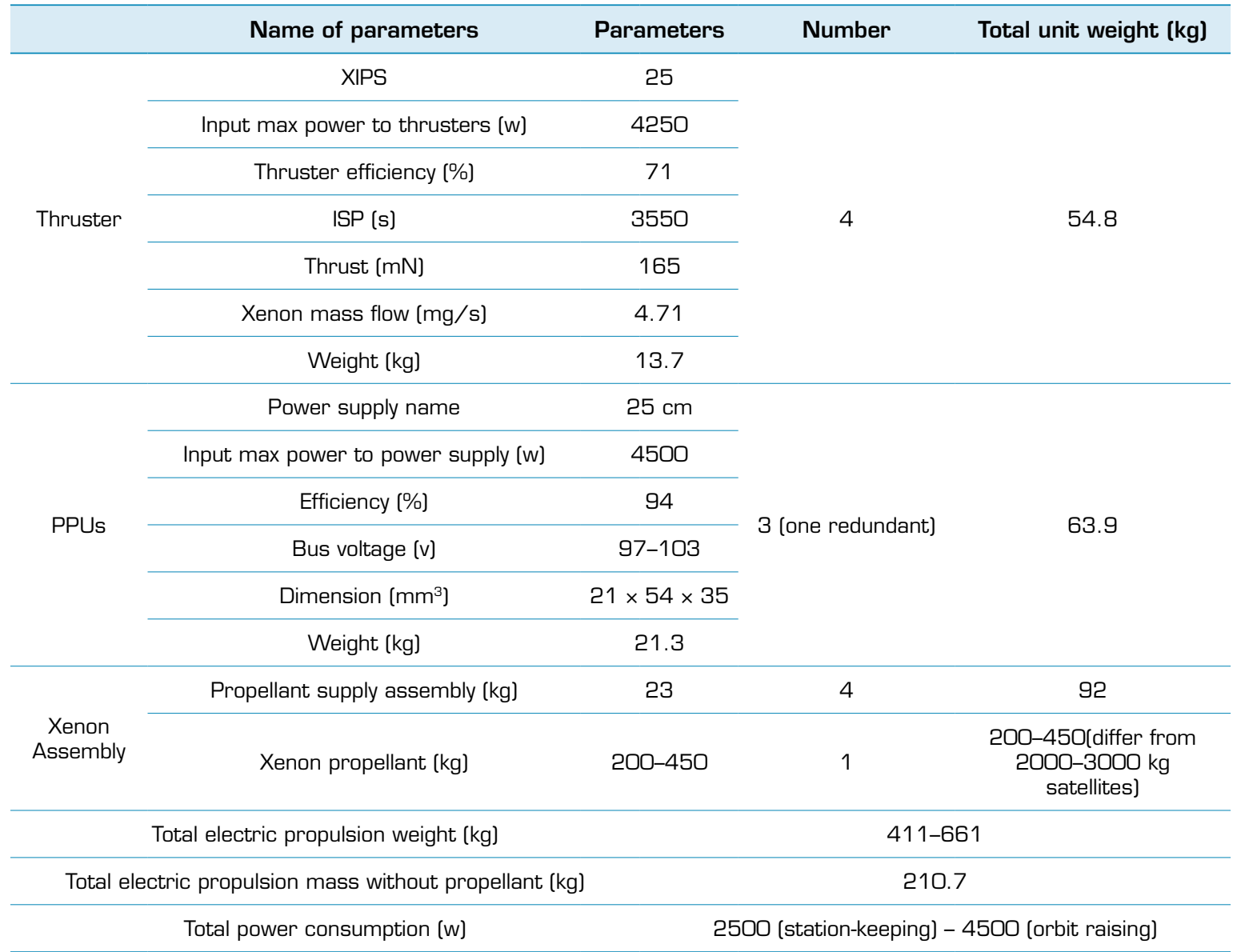

\section{Attitude determination control subsystem design}

In GEO communication satellites, ADCS is used during the mission to neutralize the internal and external disturbances, such as the third gravity effect, Earth gravity harmonies, solar radiation pressure and to maintain a high Nadir pointing accuracy for satellite, which is so critical for a functional GEO satellite (Table 26). Reaction wheels and other common satellite elements used, wherein these case all-electric satellites have had an active 3 -axis control with 0.005 -degree accuracy. Statistical data maintained rise numerous considerations for the number and type of sensors that should be used, so six sun sensors (two redundant), 2-star trackers (one redundant), four gyroscopes (two redundant), two GPS (one redundant), and four reaction wheels (one redundant) were considered. Attitude determination control subsystem design starts with calculating the satellite disturbance, in which significant external disturbances should be considered for reaction wheels momentum calculations. The momentum of reaction wheels should be ten times more than the most significant disturbance to accurately control the satellites, maintaining high nadir pointing accuracy (Wertz et al. 2011; Brow 2002). Sensors and reaction wheels were selected based on data gathered from datasheets (Table 27). 
Table 26. Geostationary Earth orbit disturbance calculations for reaction wheels momentum determination.

\begin{tabular}{ccc}
\hline Radiation solar pressure & Enharmonic earth gravity pressure & Reaction wheels momentum needed \\
\hline $1.9012 \times 10^{-5}$ & $4.1853 \times 10^{-7}$ & 4343 N.m.s $\times 10=4.343$ N.m.s \\
\hline $\begin{array}{c}\text { The biggest disturbance } \\
\text { for GEO orbit }\end{array}$ & \\
\hline
\end{tabular}

Table 27. The mass and electrical power consumption of the ADCS subsystem selected parts.

\begin{tabular}{|c|c|c|c|c|c|c|}
\hline Parameters & Numbers & $\begin{array}{l}\text { Company } \\
\text { name }\end{array}$ & $\begin{array}{l}\text { Weight } \\
\text { [kg] }\end{array}$ & $\begin{array}{l}\text { Electric power } \\
\text { consumption }(w)\end{array}$ & $\begin{array}{c}\text { Total } \\
\text { weight }(\mathrm{kg}]\end{array}$ & $\begin{array}{c}\text { Total power } \\
\text { consumption (w) }\end{array}$ \\
\hline $\begin{array}{l}\text { Reaction wheel } \\
\text { (RSI-18-220-45) }\end{array}$ & 4 (1 Redundant) & $\begin{array}{l}\text { Rockwell } \\
\text { Collins }\end{array}$ & 6.3 & $20-150$ & 25.2 & $80-600$ \\
\hline GYRO & 4 (2 Redundant) & $\begin{array}{l}\text { Honey } \\
\text { wheel }\end{array}$ & 4.7 & 32 & 20 & 128 \\
\hline Star tracker & 2 (1 Redundant) & Hydra-TC & 5.3 & 8 & 10.6 & 16 \\
\hline Coarse sun sensor & 6 (2 Redundant) & Moog Inc & 0.215 & - & 1.29 & - \\
\hline GPS & 2 (1 Redundant) & Garmin & 0.332 & 7.8 & 0.664 & 15.6 \\
\hline Total weight $(\mathrm{kg})$ & \multicolumn{6}{|c|}{57.754 (without electric boards and electric propulsion) } \\
\hline $\begin{array}{c}\text { Total power } \\
\text { consumption (w) }\end{array}$ & \multicolumn{6}{|c|}{ 240-760 (without electric board and electric propulsion) } \\
\hline
\end{tabular}

The significant difference between the ADCS of all-electric satellites to other designs is the all-electric satellite ADCS. This way, it does not require separated thrusters and the same 3-axis arm propulsion mechanism will be used for orbit maintenance and ADCS modes simultaneously. Therefore, other designs need separate thrusters requiring the additional fuel tank to separate orbital ascension mode from orbital maintenance; that ADCS subsystem is responsible for these maneuvers.

\section{Subsystems verification}

Results of conceptual parametric subsystem designs should be contrasted with statistical data or with one of the primary satellite parametric design references. For instance, Space mission engineering: the new SMAD book, which is one of the best satellitedesigning books, is used to contrast the subsystems budgets with the main power and mass calculations with the percentages of space mission engineering (Wertz et al. 2011). All percentages of different subsystems have been calculated, evaluated and illustrated in Tables 28-31. In addition, all contrasting results of percentages for parametric and new SMAD book are less than $15 \%$, which is very accurate for this level of designing. As mentioned earlier, the propulsion subsystem would be in the ADCS mass and power budget values. Consequently, there is no need to calculate separately for all-electric satellites. For electric power consumption, SMAD budgets are small since this book evaluated with the previous technology of solar cells and batteries (Wertz et al. 2011; Brow 2002). The EPS, ADCS, TT\&C subsystems verification are illustrated in Tables 28-31.

Table 28. Space mission engineering: the new SMAD power and mass budget for GEO satellites.

\begin{tabular}{ccc}
\hline Parameters & Mass [\%] & Power [\%] \\
\hline ADCS & 5-10 of total mass & 10-30 of total power \\
\hline EPS & $10-30$ of total mass & 7-30 of total power \\
\hline TT\&C and PAY & $18-30$ of total mass & 15-50 of total power \\
\hline Propulsion (chemical) without fuel & 3-8 of total mass & 0-1 of total power \\
\hline
\end{tabular}

Source: Wertz et al. (2011) and Brow (2002). 
Table 29. Electrical power subsystem comparison and verifications with design parameters and SMAD budget.

\begin{tabular}{ccc} 
Parameters & $\mathbf{2 0 0 0} \mathbf{~ k g}$ satellite & $\mathbf{3 0 0 0 ~} \mathbf{~ g}$ satellite \\
\hline Mass of parametric design $(\mathrm{kg})$ & 395.14 & 607.8 \\
\hline SMAD mass references $(\mathrm{kg})$ & 400 & 600 \\
\hline Error percentage & $1.3 \%$ & $1.3 \%$
\end{tabular}

Table 30. Attitude determination and control system with propulsion subsystem and without propellant comparison and verification.

\begin{tabular}{ccccccc}
\hline \multirow{2}{*}{ Parameters } & \multicolumn{2}{c}{ Electrical power $[\mathbf{W}$ ) } & & \multicolumn{2}{c}{ Mass (kg) } \\
\cline { 2 - 3 } \cline { 5 - 6 } & $\mathbf{8 0 0 0}$ w EOL sat & $\mathbf{1 2 0 0 0 ~ w ~ E O L ~ s a t ~}$ & & 2000 kg sat & 3000 kg sat \\
\hline Parametric design budgets & 2640 & 3160 & $1200-3600$ & & $100-250$ & $150-300$ \\
\hline References budgets & $800-2400$ & $12.3 \%$ & & $7.6 \%$ & $10.3 \%$
\end{tabular}

Table 31. Telemetry, tracking and control and payload for $2000 \mathrm{~kg}$, $8000 \mathrm{~W}$ all-electric satellite subsystem verification.

\begin{tabular}{ccc}
\hline Parameters & Total weight $(\mathrm{kg})$ & Total power consumption (W) \\
\hline Parametric design budgets $2000 \mathrm{~kg}$ all-electric satellite & 451.1 & 4190 \\
\hline References budgets for $2000 \mathrm{~kg} \mathrm{sat}$ & $\begin{array}{c}360-600(480 \text { average } \\
\text { considered })\end{array}$ & $1200-4000$ \\
\hline Error percentage & $6 \%$ & $4.8 \%$ \\
\hline
\end{tabular}

\section{CONCLUSION}

Technique for order of preference by similarity to ideal solution and AHP method, which have been conducted, showing that the test case was consistent in the range of all-electric satellite system parameters, and validating such an approach feasibility with $93.47 \%$ accuracy. Moreover, it was necessary to disclose the uncertainty about orbit specifications; hence, calculations and simulations were conducted to validate the orbit ascension, maintenance and deorbiting with the presumed statistical propellant mass data. Besides, all-electric parametric subsystem design was still necessary to validate test case design based on subsystem availability, which was revalidated with less than 13\% SMAD book percentages. The GEO all-electric satellite system conceptual design approach validated to be operational and opening the doors for detail design.

\section{AUTHORS' CONTRIBUTION}

Conceptualization: Abbasrezaee P and Saraaeb A; Methodology: Abbasrezaee P and Saraaeb A; Investigation: Abbasrezaee P and Saraaeb A; Writing - Original Draft: Abbasrezaee P and Saraaeb A; Writing - Review and Editing: Abbasrezaee P; Funding Acquisition: No funding; Resources: Abbasrezaee P; Supervision: Abbasrezaee P.

\section{DATA AVAILABILITY STATEMENT}

The statistical data is in the conference RAST 2019 paper, avaialble at: https://ieeexplore.ieee.org/abstract/document/8767854 


\section{FUNDING}

Not applicable.

\section{ACKNOWLEDGEMENT}

Not applicable.

\section{REFERENCES}

[AST] FAA Commercial Space Transportation, [COMSTAC] Commercial Space Transportation Advisory Committee (2015) 2015 Commercial Space Transportation Forecasts. Washington: FAA.

[FAA] Federal Aviation Administration (2018) The Annual Compendium of Commercial Space Transportation: 2018. Washington: FAA.

Abbasrezaee P, Mirshams M, Seyed-Zamani S (2019) Conceptual GEO Telecommunication All-Electric Satellite Design Based on Statistical Model. 2019 9th International Conference on Recent Advance in Space Technologies. IEEE, Stambul, Turkey.

Agrawal BN (1986) Design of Geosynchronous spacecraft. Upper Saddle River: Pretice Hall.

Barichard V, Gandibleux X, T'Kindt V (2009) Multiobjective Programming and Goal Programming: Theoretical Results and Practical Applications. New York: Springer.

Brown CD (2002) Elements of Spacecraft Design. Reston: AIAA.

Chetty PRK (1991) Satellite Technology and its Applications. New York: TAB books.

Corey RL, Pidgeon DJ (2009) Electric Propulsion at Space Systems/Loral. Paper presented 31th International Electric Propulsion Conference. IECP, Michigan, USA.

Davidoff MR (1990) Satellite experimenter's Handbook. Newington: American Radio Relay League.

Flood DJ, Weinberg I (1994) Advanced solar cells for satellite power systems. NASA Technical Memorandum 106777.

Goebel DM, Polk JE, Sandler I, Mikellides IG, Brophy JR (2009) Evaluation of 25-cm XIPS ${ }^{\odot}$ Thruster Life for Deep Space Mission Applications. Paper presented 31st International Electric Propulsion Conference. IEPC, Michigan, USA.

Goepel KD (2019) AHP-OS. AHP Priority Calculator. AHP Criteria, Pairwise Comparison [Online]. https://bpmsg.com/ ahp/ahp-calc.php

Griffin MD, French JR (1991) Space Vehicle Design. AIAA. https://doi.org/10.2514/4.862403

Kim V (2012) Stationary Plasma Thrusters in Russia: Problems and Perspectives. Tr Mosk Aviats Inst 60.

Leporini A, Giannetti V, Andreussi T, Pedrini D, Rossodivita A, Piragino A, Andrenucci M, Estublier D (2016) Development of a $20 \mathrm{Kw}$-class hall effect thruster. Paper presented Space Pripulsion 2016. Rome, Italy. http://www.sitael.com/wp-content/ uploads/2016/05/3125196_DEVELOPMENT_20_kW-CLASS_HET_leporini.pdf 
Lovell RR, O’Malley TA (1970) Station Keeping of High Power Communication Satellites [Online]. Technical Memorandum. Nasa. https://ntrs.nasa.gov/archive/nasa/casi.ntrs.nasa.gov/19710001770.pdf

Luebberstedt H, Bastante JC, Lau M, Beekmans S, Tata M, Schneider A (2018) Electra- Full Electric Propulsion Satellite Platform for GEO Missions. OHB Electra.

Lugtu SD (1990) Impact of ion propulsion on performance, design, testing and operation of a geosynchronous spacecraft (Master thesis). Monterey: Naval Postgraduate School. In English.

Martin DH (1996) Communication satellites 1958-1995. El Segundo: Aerospace Corp.

Martinez-Sanchez M, Pollard JE (1998) Spacecraft electric propulsion-an overview. J Propuls Power 14(5): 688-699. https:// doi.org/10.2514/2.5331

Mirshams M, Zabihian E, Zabihian AR (2015) Statistical design model (SDM) of communication satellites. Paper presented 2015 7th International Conference on Recent Advances in Space Technologies (RAST). IEEE, Istanbul, Turkey. https://doi. org/10.1109/RAST.2015.7208369

Naclerio S, Salvador JS, Such E, Avezuela R, Vara RP (2012) Small Geo Xenon Propellant Supply Assembly Pressure Regulator Panel: Test Results and Comparison with Ecosimpro Predictions. Paper presented 3rd edition of the International Conference on Space Propulsion. Bordeoux, France.

Senbely X, Wartelski M, Doubrère P, Deltour B, Cau P, Rochard F (2017) Design and Development of an Electric Propulsion Deployable Arm for Airbus Eurostar E3000 ComSat Platform. Paper presented 35th International Electric Propulsion Conference. IEPC, Atlanta, USA.

Wertz JR, Everett DF, Puschell JJ (2011) Space Mission Analysis and Design: The New SMAD. New York: Mcgraw-Hill.

Wikipedia (2021) Graveyard orbit [Online]. https://en.wikipedia.org/wiki/Graveyard_orbit

Wikipedia (2020) Analytic hierarchy process [Online]. https://en.wikipedia.org/wiki/Analytic_hierarchy process 